English institutions and only 1,189 in Wales and 1,802 in Scotland. The proportion of men in residence was 23.5 per cent and of women 42.0 per cent, compared with 22.9 per cent and 41.3 per cent, respect. ively, in the previous year, while 32,987 students $(40.9$ per cent) were in lodgings and $24,990(31 \cdot 0$ per cent) at home, compared with 40.0 per cent and 32.7 per cent in 1952-53. Of the 21,153 students admitted for the first time during 1953-54 (a decrease of 202 on 1952-53), 19,585 were reading for a first degree and 1,568 for a first diploma; and of those reading for a first degree, 1,382 were less than eighteen years of age and 10,546 were nineteen or more. Of the full-time students, 35,071 out of 47,398 men and 11,036 out of 14,775 women in England were receiving assistance by way of scholarships, exhibitions or other awards from public or private funds ; for Wales the corresponding figures are 2,799 out of 3,141 men and 1,124 out of 1,290 women; and for Scotland, 6,024 out of 10,254 men and 1,931 out of 3,744 women. Of the 60,793 full-time men students, 36.3 per cent were in arts, 22.2 per cent in pure science, 17.0 per cent in modicine and $16 \cdot 3$ per cent in technology; for the 19,809 women students the corresponding figures are $63 \cdot 7,17 \cdot 6,14 \cdot 7$ and 0.7 per cent, respectively. Medicine and dentistry claimed 49.6 per cent of the 4,682 part-time advanced students, arts $35 \cdot 6$, pure science $9 \cdot 3$ and technology $4 \cdot 8$ per cent, respectively, compared with $49 \cdot 1,33 \cdot 8$, $7 \cdot 5$ and 9.0 per cent, respectively, during 1952-53.

The recurrent income of the universities and university colleges of Great Britain increased by $£ 1,413,941$ to $£ 31,112,024$, of which $£ 21,924,115$ was from Parliamentary grants, $£ 3,724,585$ from fees, $£ 1,332,917$ from endowments, $£ 1,130,280$ from grants from local authorities and $£ 495,996$ from donations and subscriptions. Of the total income from public funds of $£ 23,054,315$ and $£ 8,057,709$ from other sources, the University of London received $£ 6,957,728$ from public, and $£ 2,462,874$ from other, sources ; the University of Cambridge similarly received $£ 1,436,133$ and $£ 1,332,864$; for Oxford the corresponding figures are $£ 1,383,461$ and $£ 636,418$; Manchester, $£ 1,125,886$ and $£ 270,863$; Durham, $£ 999,429$ and $£ 324,969$; Leeds, $£ 933,533$ and $£ 268,480$; Liverpool, $£ 917,590$ and £254,203; Birmingham, £900,815 and £240,216; Bristol, $£ 819,537$ and $£ 319,179$; Sheffield, $£ 579,598$ and $£ 170,268$; Nottingham, $£ 500,005$ and $£ 105,136$; and Reading, £546,373 and $£ 65,241$. No other English university or university college had an income exceeding half a million pounds, but for the four universities in Scotland the corresponding figures are : Aberdeen, $£ 509,000$ and $£ 126,529$; Edinburgh, $£ 1,093,169$ and $£ 373,686$; Glasgow, $£ 1,114,126$ and $£ 332,078$; and St. Andrews, $£ 545,260$ and $£ 116,100$. The University of Wales, including the Welsh National School of Medicine, received $£ 1,149,707$ from public funds and $£ 302,169$ from other sources. Non-recurrent Treasury grants during the year, in respect of capital expenditure, mainly on buildings, sites, equipment and professional fees, amounted to $£ 5,516,356$ compared with $£ 5,746,470$ in $1952-53$.

Of the total expenditure of $£ 30,260,235$-an increase of $£ 1,559,801$, or $5 \cdot 4$ per cent on 1952-53-administration accounted for $7 \cdot 3$ per cent, departmental maintenance $69 \cdot 4$ per cent, maintenance of premises 12.7 per cent, and miscellaneous expenditure 9.4 per cent. Capital expenditure met from income amounted to $£ 358,289$ and allocations to reserve to $£ 342,397$; for 1952-53 these figures were $£ 334,516$ and $£ 334,015$, respectively. Departmental maintenance, which includes salaries of teaching staff, payments for superannuation, the running costs of laboratories, lecture rooms, libraries and museums and the supply of materials, apparatus, books, specimens, etc., increased by $£ 1,244,181$ to $£ 21,005,981$, the major increase being $13 \cdot 2$ per cent on departmental wages of technicians and laboratory assistants. Salaries and superannuation of teaching staff amounted to $£ 13,616,426$ compared with $£ 13,169,879$ in 1952-53, but expenditure on repairs and maintenance of buildings only inereased by $4 \cdot 1$ per cent to $£ 1,953,017$, although that on rates, insurance, heat, light, water, etc., was up by 9.0 per cent to $£ 1,953,017$.

Library expenditure, excluding general maintenance of library buildings, etc., and rates, heat, light, repairs, etc., amounted to $£ 1,203,231$, or $4 \cdot 0$ per cent of the total expenditure compared with $£ 1,118,428$ or 3.9 per cent in $1952-53,3.8$ per cent during 1951-52 and 3.7 per cent during 1950-51. Of this, $£ 600,647$ was for salaries and wages, $£ 147,669$ for periodicals and $£ 97,229$ for bindings. Of the $£ 290,581$ expended on books, $£ 75,652$ was in the schools and colleges of the University of London, including $£ 11,732$ at the Central Library, $£ 11,890$ at the London School of Economics, $£ 9,132$ at University College, and $£ 5,963$ at the School of Oriental and African Studies. The University of Oxford spent

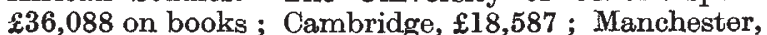
$£ 14,256$; Liverpool, $£ 9,959$; Birmingham, $£ 8,686$; Loeds, £9,150 ; Durham, £10,829 ; Bristol, £8,441 ; and Southampton, $£ 7,509$. Expenditure on books and periodicals at a number of English universities and university colleges decreased rather than increased during the year, and increases in general are scarcely in proportion to the mounting costs of both books and periodicals. Only the Universities of London $(£ 39,814)$, Oxford $(£ 13,530)$ and Cambridge $(£ 12,448)$ spent more than $£ 10,000$ on periodicals, and only Birmingham $(£ 7,110)$, Leeds $(£ 5,108)$ and Manchester $(£ 6,250)$ more than $£ 5,000$. The University of Wales spent $\mathfrak{1 2 , 8 0 5}$ on books and $£ 8,040$ on periodicals. In Scotland, Edinburgh spent $£ 13,930$ on books and $£ 7,212$ on periodicals; Glasgow, $£ 12,943$ and $£ 9,559$; St. Andrews, $£ 10,650$ and $£ 4,336$; and Aberdeen, $£ 8,089$ and $£ 3,939$.

\section{INTERNATIONAL SCIENTIFIC RADIO UNION}

\section{PROCEEDINGS OF THE ELEVENTH GENERAL ASSEMBLY}

7 HE eleventh General Assembly of the International Scientific Radio Union was held at The Hague during August 23-September 2, 1954, when some three hundred delegates from twenty-two countries participated under the chairmanship of Father P. Lejay, who was re-elected president of the Union until the next Assembly in 1957.

The main functions of the Union are to promote and organize radio research requiring international co-operation and to encourage the setting-up of common methods of measurement with standardized apparatus. The work is carried out by seven Commissions, and these are concerned with specific aspects of radio research defined by their titles, which were carefully considered and revised at the recent assembly. The present titles, together with the names of the chairmen elected for the session 
1954-57 are as follows: I, Radio Measurement and Standards (Dr. B. Decaux); II, Radio and Troposphere (Dr. R. L. Smith-Rose) ; III, Ionospheric Radio (Dr. D. F. Martyn); IV, Radio Noise of Terrestrial Origin (Mr. J. A. Ratcliffe); V, Radio Astronomy (Dr. M. Laffineur); VI, Radio Waves and Circuits (Dr. S. Silver); VII, Radio Electronics (Prof. G. A. Woonton).

The proceedings of the eleventh General Assembly are being published in eight parts available in either French or English. The first seven parts are to be devoted to the Commission activities; while Part 8, which has just been issued, contains a full account of the administrative proceedings with information on other activities of the Union (10, Part 8 (1955); pp. 125 ; obtainable from the General Secretary of the Union at 42 Rue des Minimes, Brussels; 14s. $6 d$. or 100 Belg. franes).

Although the Union does not now publish the scientific papers which are read and discussed at a General Assembly, a list of titles and authors of the 296 papers and reports submitted at The Hague meeting is given in Part 8 ; and it is to be noted that the reports of national committees will be published in full in Parts 1-7 according to the Commissions to which they refer. The Union also publishes, six times a year, an Information Bulletin, in which are recorded the activities and progress of the Union between successive General Assemblies.

The administrative proceedings (Part 8), referred to above, contains all the resolutions and recommendations adopted by the General Assembly of 1954. Among these is a recommendation accepted from Commission I that the value of $299792 \pm 2$ $\mathrm{km}$./sec. should be used in all scientific work for the velocity of electromagnetic waves in a vacuum. It was further resolved that all national laboratories in a position to do so should co-operate in making a comparison of standards of power measurement at frequencies of 3,000 and $10,000 \mathrm{Mc} / \mathrm{s}$.

A full report of the discussions which led up to these recommendations is contained in Part 1 of the proceedings, which was published a few months ago (10, Part 1 (1955); pp. 57; 8s. 8d. or 60 Belg. francs). This Part 1 contains all the national reports submitted to Commission I, together with the minutes of the meetings of the Commission at The Hague and the resolutions submitted to the General Assembly for adoption. In response to a request received from the International Radio Consultative Committee, it was recommended that members of the International Scientific Radio Union should make observations on the service areas and mutual interference zones of standard frequency transmissions, and also on the type of modulation used by the stations at present in operation. A study of the results of such observations should be of great assistance in the establishment and operation of an effective standard frequency and time service on a world-wide basis.

Among the other activities of the Union reported in Part 1 of the proceedings is an account of the meetings of the committee appointed to consider the programme of work for the forthcoming International Geophysical Year during 1957-58, and brief accounts of the meetings of the Mixed Commission on the Ionosphere and of the Joint Commission on Radio Meteorology held in 1954. The Union committee on the International Geophysical Year has considered various matters relating to the proposed programmes of observations in connexion with meteorology, aurora, ionospheric absorption and 'winds', radio star scintillations, meteors, atmospherics and terrestrial noise. It has also given preliminary consideration to the question of presentation and publication of the results obtained, and made recommendations on all these matters to the international committee on the International Geophysical Year, which will meet again shortly to formulate the recommended world-wide programme.

It is clear from the two parts ( 1 and 8 ) of the proceedings already available that they comprise excellent surveys of the relevant fields of radio research, fully documented with references to the original scientific published papers, and the appearance of the remaining parts dealing with the work of Commissions II-VII will be awaited with interest by students and research workers in the field of scientific radio.

R. I. SMITH-RosE

\section{PRODUCTION AND MEASUREMENT OF ULTRA-HIGH VACUA}

QEFORE 1950, pressures of the order of $10^{-7} \mathrm{~mm}$. of mercury were considered high vacua, and although, undoubtedly, lower pressures were obtained, it was not possible to measure them because the most sensitive vacuum gauges were no longer reliable at such low pressures. To-day, it is possible to produce and measure pressures of $10^{-8}-10^{-11} \mathrm{~mm}$. of mercury, to estimate pressures as low as $10^{-12} \mathrm{~mm}$. and, in the case where interest is concentrated on the chemically active gases present in the space to be evacuated, to estimate partial pressures of these gases of the order of $10^{-14} \mathrm{~mm}$.

A brief but interesting review of these recent developments, together with a summary of the operation of basic pumping apparatus, is given by Dr. J. A. Becker in the January number of the Bell Laboratories Record (33, No. 1; 1955). The combination of fore-pump, mercury diffusion pump and cold trap enables pressures of less than $10^{-8} \mathrm{~mm}$. to be reached. With the Mcleod gauge, pressures down to about $10^{-6} \mathrm{~mm}$. can be accurately measured, and with the ionization gauge, introduced in 1916, lower pressures by extrapolation can be determined. The ionization gauge fails, however, when the pressure reaches $10^{-8} \mathrm{~mm}$., and work since 1950 has shown that ionizing currents, produced by soft X-rays striking the plate of the gauge, and the emission of photo electrons together with an electron current that reaches the plate even when the plate is at a negative potential with respect to the cathode, which are independent of the pressure, constitute the limiting factors. Bayard and Alpert have proposed an arrangement by which these currents may be minimized. The plate is reduced to a fine wire and surrounded by a cylindrical grid with the filament placed outside the grid. With this modified type of ionization gauge, pressures of $10^{-11} \mathrm{~mm}$. of mercury have been measured.

To attain these ultra-high vacua it becomes important to know the amount of, and sources of, residual gas present in the system to be evacuated, and Dr. Becker describes four such sources. They are the release of gas from the cold trap; the diffusion of dissolved gases out of the glass and metal parts of the system; the release of gases adsorbed 